\title{
NUTRITIONAL ASSESSMENT IN PATIENTS WITH EARLY-ONSET AUTOSOMAL DOMINANT ALZHEIMER'S DISEASE DUE TO PSEN1- E280A GENETIC VARIANT: A CROSS-SECTIONAL STUDY
}

\author{
M. Gómez-Vega', , E. Garcia-Cifuentes ${ }^{2,3}$, D. Aguillon ${ }^{1,2}$, J.E. Velez'2, A. Jaramillo-Jimenez ${ }^{1,2,4,5}$, \\ D. Vasquez ${ }^{2,6}$, C. Gómez-Henck ${ }^{2}$, C. Andrés Tobon ${ }^{1}$, G.C. Deossa Restrepo ${ }^{7}$, F. Lopera ${ }^{2}$
}

\begin{abstract}
Background: Weight loss and malnutrition are frequent findings in late-onset and sporadic presentations of Alzheimer's Disease (AD). However, less is known about nutritional status in Early-Onset Autosomal Dominant AD (EO-ADAD). Objective: To analyze the association between nutritional status and other clinical and sociodemographic characteristics in individuals with a genetic form of EO-ADAD. Design, settings, and participants: Cross-sectional study with 75 non-institutionalized participants from a cohort of Autosomal Dominant $\mathrm{AD}$ (13 with mild cognitive impairment and 61 with dementia, ages from 38 to 67 years) underwent a structured clinical assessment with emphasis on nutritional status. Measurements: Primary outcome was nutritional status and it was measured using the Mini Nutritional Assessment (MNA). Patients were categorized according to MNA total score, as undernourished $(\mathrm{MNA} \leq 23.5)$ and well-nourished $(\mathrm{MNA} \geq 24)$. Sociodemographic and clinical variables identified as potential predictors or confounders of nutritional status were also collected. Results: Undernourishment by MNA was present in 57.3\% of the sample. Forty-two percent of participants had abnormal BMI values considered lower than 18.5 or higher than $24.9 \mathrm{~kg} / \mathrm{m}^{2}$. Total BMI values were similar in well and undernourished patients (median 24.2 IQR 3.59 and median 23.9 IQR 4.42, respectively, $\mathrm{p}=0.476$ ). When comparing well and undernourished groups, we found statistically significant differences for variables: severity of dementia $(\mathrm{p}=0.034)$, frailty $(\mathrm{p}=0.001)$, multimorbidity $(\mathrm{p}=0.035)$ and, polymedication $(\mathrm{p}=0.045)$. Neither adjusted logistic regression nor the Poisson regression showed that any clinical or sociodemographic variables explained undernourishment. Conclusions: Undernourishment was a frequent finding in our sample of EO-ADAD, especially in later stages of the disease. Patients with polymedication, multimorbidity, frailty and severe dementia show differences in their nutritional status with a tendency to be more frequently undernourished. Further studies with larger sample sizes are needed to establish this association.
\end{abstract}

Key words: Autosomal Dominant Alzheimer's Disease, Mini Nutritional Assessment, malnutrition.

\section{Introduction}

Alzheimer's Disease (AD) is the main cause of dementia worldwide (1). Less than $1 \%$ of all $\mathrm{AD}$ cases are due to a genetic variant with familial aggregation. 1. Grupo Neuropsicología y Conducta, Facultad de Medicina, Universidad de
Antioquia, Institución Prestadora de Servicios de Salud - IPS Universitaria,
Medellín, Colombia; 2. Grupo Neurociencias de Antioquia, Facultad de Medicina,
Universidad de Antioquia, Medellín, Colombia; 3. Semillero de Neurociencias
y Envejecimiento, Facultad de Medicina, Instituto de Envejecimiento, Pontificia
Universidad Javeriana, Bogotá, Colombia; 4 . Centre for Age-Related Medicine
(SESAM), Stavanger University Hospital. Stavanger, Norway; 5. Faculty of Health
Sciences, University of Stavanger. Stavanger, Norway; 6. Grupo de investigación
en Epidemiología y Bioestadística, Universidad CES, Medellín, Colombia;
7. Escuela de nutrición y dietética, Universidad de Antioquia, Medellín, Colombia.
ORCID digit: Manuela Gómez-Vega: 0000-0002-2000-4901; Elkin Garcia-Cifuentes:
0000-0003-4214-0266; David Aguillon: 0000-0003-2283-536X; Juan Esteban Velez:
0000-0002-0800-5709; Alberto Jaramillo-Jimenez: 0000-0001-5374-6410; Daniel
Vasquez: 0000-0002-2586-162X; Clara Gómez Henck: 0000-0003-0848-8330; Carlos
Andrés Tobon: 0000-0002-5787-6279; Gloria Cecilia Deossa Restrepo: 0000-0002-
1635-1601; Francisco Lopera: 0000-0003-396-1484

Corresponding author: Manuela Gómez Vega, Grupo Neuropsicología y Conducta, Facultad de Medicina, Universidad de Antioquia, Institución Prestadora de Servicios de Salud - IPS Universitaria, Medellín, Colombia E:mail: manugomezvega@gmail.com; Tel: (+57) 319 5245304; Fax: (+574) 2196444

Received September 19, 2020

Accepted for publication May 3, 2021
However, these forms of dementia are usually more severe and have an earlier onset (before age 65) (2). As a case in point, the Group of Neurosciences of Antioquia (GNA by its name in Spanish: Grupo de Neurociencias de Antioquia) in Colombia, has longitudinally followed around 6000 individuals at risk of Early-Onset Autosomal Dominant AD (EO-ADAD), 20\% of them potentially carrying a single genetic variant, E280A (Glu280Ala) in Presenilin 1 (PSEN1), responsible for the disease (3). In this population, the mean age of onset for Mild Cognitive Impairment (MCI) is 44 years of age and 49 years of age for dementia (4), which is approximately 20 years younger than in late-onset $\mathrm{AD}(2)$.

Changes in nutritional status and weight loss have been widely studied before the onset and during the course of sporadic AD (5) representing a mortality predictor (6). Some mechanisms involved are neurodegeneration of specific brain regions (7), inflammatory processes (8) and, olfactory and taste dysfunction (9). Besides, some dementia-specific symptoms such as executive function and planning 
impairments, amnesia, behavioral and neuropsychiatric disorders $(10,11)$ dysphagia, side effects of pharmacotherapy (12), among others, lead to reduced dietary intake and malnutrition.

Malnutrition is related to modification of many epigenetic markers, resulting in the development of complex systemic disorders such as diabetes, obesity and hypertension: all related to higher cardiovascular risk and greater progression of $\mathrm{AD}$ (13-15). Malnutrition increases mortality rates in adults with dementia, causes reduced muscle mass, loss of autonomy, increased falls, decubitus ulcers, systemic infections (11) and rapid cognitive decline (16).

Approximately $44 \%$ of cognitively impaired elderly subjects are at risk of malnutrition and 15\% suffer from it, albeit with variations in measurement from one region to another (17). Despite wide availability of information on malnutrition in late and sporadic forms of $\mathrm{AD}$, only a few studies have assessed nutritional variables either in early-onset AD or in preclinical stages of ADAD (1822 ). Studying the relationship between nutrition and EO-ADAD may provide a basis for effective preventive strategies as a public health priority against malnutrition, as well as a better understanding of morbimortality risk, due more to dementia than aging itself.

The purpose of the current study is to analyze the association between nutritional status in individuals with a genetic form of EO-ADAD and some clinical and sociodemographic potential determinants of malnutrition.

\section{Methods}

\section{Study design and population}

This is a cross-sectional study with a convenience sample of 75 individuals. The study population consisted of a sub-group of the longitudinal cohort of participants with EO-ADAD due to a genetic variant in PSEN1 (E280A) followed by the GNA. Major eligibility criteria included: diagnosis of cognitive impairment provided by an expert neurologist based on clinical and neuropsychological aspects $(23,24)$, carrier status of the PSEN1-E280A genetic variant and written informed consent from the participant or authorized proxy. Exclusion criteria were: functional limitation defined as a Global Deterioration Scale $\geq 6$ (25) and clinical diagnosis of cerebrovascular disease.

Data was collected from records of 75 noninstitutionalized patients ( 13 with $\mathrm{MCI}$ and 62 with dementia) participating in the ongoing project of the GNA called "Characterization of frailty syndrome in a population with early-onset Alzheimer's Disease due to a genetic variant in PSEN1-E280A, using the evaluation methodology: Multimodal Approach for the Patient with Alzheimer's and other Dementias (AMPAD)", in Spanish: "Caracterización del síndrome de fragilidad en población con Enfermedad de Alzheimer de inicio precoz por variante genética PSEN1- E280A usando la metodología de evaluación: Abordaje Multimodal al Paciente con Alzheimer y otras Demencias (AMPAD)". The genotypification of PSEN1-E280A variant is regularly conducted by the GNA using the molecular method PCR-RFLP (26), in all the members of the kindred that is being longitudinally followed since the 1990s (3).

Written informed consent was obtained from participants and their caregivers before study enrollment. The study was approved by the ethics committee of the Institute of Medical Research - School of Medicine of the University of Antioquia act $005 / 2020$.

\section{Clinical assessment}

Demographic and clinical data were obtained by a trained physician with a simultaneous interview of both participants and their caregivers. Polymedication was defined as taking $\geq 3$ medications (24) and multimorbidity as having $\geq 2$ chronic conditions (29). Hypertension, dyslipidemia and diabetes mellitus 2 were assessed by having it recorded in a previous medical record.

Frailty status was assessed through the Short Physical Performance Battery (SPPB) and the Timed Up and Go Test following standardized methods. The SPPB classifies individuals as non-frail or pre-frail/frail with a total score $>9$, and $\leq 9$, respectively (30). Participants who could not complete the SPPB because of major cognitive impairment were assessed using gait speed, classifying those with speed on a 6 meter walk $<1 \mathrm{~m} / \mathrm{s}$ as pre-frail/ frail (31).

Anthropometric measures included brachial, calf and abdominal circumference obtained with a measuring tape SECA 101 (sensibility $0.1 \mathrm{~cm}$ ). The abdominal perimeter was measured at the midpoint between the last rib and the upper border of the iliac crest and was categorized as normal or at risk of metabolic syndrome (women $\geq 80$, men $\geq 90 \mathrm{~cm}$ ) (32). Weight was measured in light clothing to the nearest $0.1 \mathrm{~kg}$ using SECA 813 electronic scale (sensibility $0.1 \mathrm{~kg}$ ) and height using a wall-mount SECA 206 stadiometer. World Health Organization`s classification was used for Body Mass Index (BMI) (body weight [ $\mathrm{kg}$ ] divided by body height squared [m2]): underweight $<18.5$, normal weight $18.5-24.9$, overweight $25-29.9$ and obesity $\geq 30$ (33).

\section{Main outcome measure}

Main outcome for nutritional status was the total score on the Mini Nutritional Assessment ${ }^{\circledR}$ Guideline (MNA) questionnaire (including both screening and assessment). MNA has been validated for the evaluation of nutritional status of frail elderly including those with $\operatorname{AD}(17,34)$. It has shown high sensitivity, specificity, and positive predictive value $(96 \%, 98 \%$ and, $97 \%$ respectively) (35). MNA has also been used in younger populations 
Table 1

Demographic and clinical characteristics of the sample according to nutritional status

\begin{tabular}{|c|c|c|c|c|}
\hline \multicolumn{5}{|c|}{ n $(\%)$} \\
\hline Variable & Well-nourished, 32 (42.6) & Undernourished, 43 (57.3) & Overall, 75 (100) & p-value* \\
\hline Gender & & & & 0.101 \\
\hline Female & $14(43.8)$ & $27(62.8)$ & $41(54.7)$ & - \\
\hline Male & $18(56.2)$ & $16(37.2)$ & $34(45.3)$ & - \\
\hline Severity of dementia & & & & 0.034 \\
\hline$M C I$ & $9(28.1)$ & $4(9.3)$ & $13(17.3)$ & $\begin{array}{c}\text { vs. Mild: } 0.768 \\
\text { vs. Moderate: } 0.238 \\
\text { vs. Severe: } \mathbf{0 . 0 3 5}\end{array}$ \\
\hline Mild & $11(34.4)$ & $10(23.3)$ & $21(28.0)$ & $\begin{array}{c}\text { vs. Moderate: } 0.724 \\
\text { vs. Severe: } 0.163\end{array}$ \\
\hline Moderate & $8(25.0)$ & $14(32.6)$ & $22(29.3)$ & vs. Severe: 0.706 \\
\hline Severe & $4(12.5)$ & $15(34.9)$ & $19(25.3)$ & - \\
\hline Frailty & & & & 0.001 \\
\hline Non-frail & $27(84.4)$ & $19(44.2)$ & $46(61.3)$ & - \\
\hline Pre-frail/frail & $5(15.6)$ & $22(51.2)$ & $27(36.0)$ & - \\
\hline Missing & $0(0)$ & $2(4.7)$ & $2(2.7)$ & - \\
\hline \multicolumn{4}{|c|}{ Multimorbidity ( $\geq 2$ chronic conditions) } & 0.035 \\
\hline No & $22(68.8)$ & $19(44.2)$ & $41(54.7)$ & - \\
\hline Yes & $10(31.2)$ & $24(55.8)$ & $34(45.3)$ & - \\
\hline \multicolumn{4}{|c|}{ Polymedication ( $\geq 3$ medications) } & 0.045 \\
\hline No & $25(78.1)$ & $24(55.8)$ & $49(65.3)$ & - \\
\hline Yes & $7(21.9)$ & $19(44.2)$ & $26(34.7)$ & - \\
\hline \multicolumn{4}{|l|}{ BMI classification $¥\left(\mathrm{~kg} / \mathrm{m}^{2}\right)$} & 0.294 \\
\hline Underweight, $(<18.5)$ & $0(0)$ & $2(4.7)$ & $2(4.7)$ & - \\
\hline Normal weight, (18.5-24.9) & $19(59.4)$ & $24(55.8)$ & $43(57.3)$ & - \\
\hline Overweight, (25--29.9) & $12(37.5)$ & $13(30.2)$ & $25(33.3)$ & - \\
\hline Obesity $(\geq 30)$ & $1(3.1)$ & $4(9.3)$ & $5(6.7)$ & - \\
\hline \multicolumn{4}{|l|}{ Hypertension } & 0.181 \\
\hline No & $26(81.2)$ & $29(67.4)$ & $55(73.3)$ & - \\
\hline Yes & $6(18.8)$ & $14(32.6)$ & $20(26.7)$ & - \\
\hline \multicolumn{4}{|l|}{ Dyslipidemia } & 0.340 \\
\hline No & $27(87.5)$ & $34(79.1)$ & $62(82.7)$ & - \\
\hline Yes & $4(12.5)$ & $9(20.9)$ & $13(17.3)$ & - \\
\hline \multicolumn{4}{|l|}{ Diabetes mellitus 2} & 0.179 \\
\hline No & $29(90.6)$ & $42(97.7)$ & $71(94.7)$ & - \\
\hline Yes & $3(9.4)$ & $1(2.3)$ & $4(5.3)$ & - \\
\hline \multicolumn{4}{|c|}{ At risk of metabolic syndromex } & 0.307 \\
\hline No & $7(21.9)$ & $14(32.5)$ & $21(28.0)$ & - \\
\hline Yes & $21(65.6)$ & $24(55.8)$ & $45(60.0)$ & - \\
\hline \multirow{2}{*}{\multicolumn{2}{|c|}{ Missing }} & $5(11.6)$ & $9(12.0)$ & - \\
\hline & & \multicolumn{3}{|l|}{ Median (IQR } \\
\hline Variable & Well-nourished & Undernourished & Overall & p-Value \\
\hline Age & $49(7.5)$ & $49(7.5)$ & $49(8)$ & 0.699 \\
\hline Years of education & $8.00(7.00)$ & $6.00(7.00)$ & $7.00(6.50)$ & 0.211 \\
\hline BMI $\left(\mathrm{kg} / \mathrm{m}^{2}\right)$ & $24.2(3.59)$ & $23.9(4.42)$ & $24.1(4.37)$ & 0.476 \\
\hline
\end{tabular}


(36). Brachial and calf circumferences were measured as described in the MNA guideline (37). It classifies patients into well-nourished (MNA score $>23.5$ ), at risk of malnutrition (MNA score=17.0-23.5), or malnourished (MNA score $<17$ ).

\section{Neuropsychological assessment}

All participants evaluated in the longitudinal followup of the Group of Neurosciences of Antioquia undergo a standardized neuropsychological assessment by a trained clinician based on the research group protocol (38). For the dementia stage grading, we collected neuropsychological data from visits in the prior three months to the clinical evaluation. We included: MiniMental State Examination from 0 to 30, where higher values indicate a better cognitive function (39), Global Deterioration Scale used to establish cognitive and functional impairment ranging from 1 to 7 , and Barthel Index (40) for impairment in basic activities of daily living, lower scores indicating greater dependency.

\section{Statistical analysis}

Absolute and relative measures of demographic and clinical variables were obtained for qualitative data, central tendency and dispersion measures were evaluated using median and interquartile range. For statistical purposes, we categorized subjects according to the MNA total score into well-nourished (MNA score $>23.5$ ), and undernourished (MNA score $\leq 23.5$ ) groups. Therefore, the undernourished group consisted of both: subjects at risk of malnutrition $(\mathrm{n}=37)$ as well as those classified as malnourished $(n=6)$ according to the MNA total score.

To compare demographic and clinical variables between the well-nourished and undernourished groups, group differences in demographic (i.e. age, gender, and years of education) and clinical variables (i.e. severity of dementia, frailty, multimorbidity, polymedication, BMI, diagnosis of diabetes mellitus type 2, hypertension, dyslipidemia and risk of metabolic syndrome) were evaluated with independent samples Mann-Whitney U or T-test (depending on normal distribution according to Shapiro Wilk test) and Chi-square test for continuous and categorical variables, respectively.

To analyze the association between nutritional status and clinical and demographic characteristics, we performed a bivariate and multivariate analysis using logistic regression models. Unadjusted models included each clinical and demographic variable as explicative variables and nutritional status as a binary outcome (i.e. well-nourished and undernourished categories). The variables included in the bivariate analysis were used to adjust the estimators in the multivariate analysis and all of them had Variance Inflation Factors (VIF) values smaller than 2. Thus, an adjusted model included relevant demographic and clinical predictors mutually adjusted, and nutritional status as a binary outcome. Besides, these results were also verified by estimating the Prevalence Ratios (instead of Odds ratios) for undernutrition and well-nourishment groups, thus, Poisson regressions with robust variance estimation using the White's estimator with an Omega value of 1 (Supplementary material 1), following previously published recommendations for cross-sectional designs with a binary outcome $(41,42)$. However, no major differences were evidenced between both methods. All the hypothesis tests were performed using an alpha value of 0.05 and a confidence interval of 0.95 . The statistical analysis was performed using $R$ software (version 3.6.1) (43).

\section{Results}

The demographic and clinical characteristics of the sample are shown in Table 1 . Ages varied from 38-67 years with a median of $=49$ years of age, IQR $=8$. We found an overall frequency of undernutrition of $57.3 \%$ $(n=43)$ in patients with EO-ADAD by MNA. Of those in the undernourished group, $67.5 \%(n=29)$ were in later stages of $\mathrm{AD}$ (moderate and severe dementia). Forty-two percent $(n=32)$ of the sample had abnormal BMI values distributed as underweight $n=2$, overweight $n=25$, obesity $\mathrm{n}=5$. BMI values were similar in well and undernourished patients (median $=24.2 \mathrm{IQR}=3.59$ and median $=23.9 \mathrm{IQR}=$ 4.42 , respectively, $p=0.476$ ).

There were statistically significant differences for the variables: severity of dementia, frailty, multimorbidity and, polymedication when comparing well and undernourished groups. Undernourished patients tend to be more commonly frail $(n=22,52.1 \%)$ than wellnourished patients $(n=5,15.6 \%) p=0.001$. Likewise, the differences between the groups regarding severity of dementia were significant $(\mathrm{p}=0.034)$, particularly when comparing MCI vs. severe dementia $(\mathrm{p}=0.035)$. For the other variables, we found no statistically significant differences (see Table 1).

\section{Associations between clinical variables and nutritional status}

In the unadjusted bivariate analysis, the variables moderate or severe dementia, frailty, polymedication, and multimorbidity were associated with the undernourished category. However, after adjusting for all clinical variables included in the analysis, there was no significant association for any of the variables (Table 2).

\section{Discussion}

Our study analyses the association between nutritional status in individuals with a genetic form of EO-ADAD (median age 49 years) and some clinical and sociodemographic characteristics. Overall, we found undernutrition to be present in $57.3 \% \quad(n=43)$ of the 
Table 2

Associations between clinical and sociodemographic variables with undernourishment

\begin{tabular}{|c|c|c|c|c|c|c|}
\hline & & & & \multicolumn{3}{|c|}{ Adjusted $^{*}$} \\
\hline & OR & $95 \% \mathrm{CI}$ & $p$ value & OR & $95 \% \mathrm{CI}$ & p value \\
\hline Gender, male & 0.71 & $(0.47 ; 1.09)$ & 0.121 & 0.95 & $(0.59 ; 1.51)$ & 0.814 \\
\hline Age & 0.99 & $(0.96 ; 1.03)$ & 0.720 & 0.97 & $(0.93 ; 1.01)$ & 0.110 \\
\hline Years of education & 0.97 & $(0.92 ; 1.01)$ & 0.168 & 0.98 & $(0.93 ; 1.04)$ & 0.576 \\
\hline Moderate or severe dementia & 1.72 & $(1.09 ; 2.7)$ & 0.019 & 1.50 & $(0.86 ; 2.62)$ & 0.149 \\
\hline Pre-frailty/frailty & 1.97 & $(1.33 ; 2.93)$ & 0.001 & 1.48 & $(0.9 ; 2.46)$ & 0.124 \\
\hline $\begin{array}{l}\text { Multimorbidity ( } \geq 2 \text { chronic condi- } \\
\text { tions) }\end{array}$ & 1.52 & $(1.02 ; 2.27)$ & 0.039 & 1.23 & $(0.68 ; 2.25)$ & 0.495 \\
\hline Polymedication ( $\geq 3$ medications) & 1.49 & $(1.03 ; 2.17)$ & 0.036 & 1.06 & $(0.67 ; 1.68)$ & 0.798 \\
\hline Hypertension & 1.33 & $(0.9 ; 1.95)$ & 0.150 & 1.11 & $(0.63 ; 1.98)$ & 0.713 \\
\hline Dyslipidemia & 1.26 & $(0.82 ; 1.95)$ & 0.291 & 1.11 & $(0.66 ; 1.89)$ & 0.688 \\
\hline At risk of metabolic syndrome & 0.80 & $(0.53 ; 1.21)$ & 0.291 & 0.78 & $(0.46 ; 1.34)$ & 0.367 \\
\hline
\end{tabular}

$\mathrm{OR}=$ Odds Ratio; $95 \% \mathrm{CI}=95 \%$ confidence interval. * All the variables included in the bivariate analysis were used to adjust the estimators in the multivariate analysis.

sample. We did not find other studies that use MNA in any kind of early-onset dementia. Nevertheless, these results are comparable to previous studies conducted in elderly adults with cognitive impairment due to AD, which show a similar frequency of undernutrition by MNA score similar to the one found: in Korea $(46 \%)$ (44), Japan (57\%) (10), Netherlands (14.1\% ) (45), in France $(21-25 \%)(17,34)$, and as high as $96 \%$ in Italy (46). These differences might be explained by disease duration, clinical-stage, study design and culture. However, considering that dementia is a common variable between these studies and our study, we suggest that undernutrition might be present independently from age of onset, and perhaps it is attributable by different mechanisms to the dementia syndrome.

Thirty-two patients $(42.6 \%)$ had abnormal BMI values (including under/overweight and obesity), which is consistent with a study of cardiovascular risk factors of a French cohort of early-onset AD (18). Furthermore, it is remarkable that $\mathrm{n}=13(40 \%)$ of these patients with abnormal BMI values were part of the well-nourished group, which could be probably explained because the BMI cut-off values of the MNA differ from the WHO reference values for middle-aged adults. After analyzing BMI as a continuous variable, we did not observe any differences between the wellnourished and undernourished groups. Likewise, we did not find any differences when comparing brachial, calf and abdominal circumferences. Therefore, despite the common use of BMI and other anthropometric variables to classify nutritional status, these results suggest, that anthropometric variables (as an independent measure) are not well related to nutritional status according to MNA in this population of middle-aged adults with dementia. For clinical purposes, we suggest, the importance of complementing the nutritional evaluation with both MNA and BMI in this population. Future studies are needed to address results adapting thresholds of BMI, brachial, and calf circumferences on the MNA in early-onset dementia, to increase its sensibility.

The tendency of frail patients to be more likely in the undernourished group found in our study has been previously proven in older adults, leading to the consideration of MNA as an appropriate tool to measure frailty (47). Likewise, multimorbidity and therefore polypharmacy have been postulated, by different mechanisms, to exert a negative impact on nutrition, due to disorders in food intake, insufficient absorption of nutrients and indirect metabolic effects $(21,48)$. Nevertheless, in the multivariate analysis, no association was found when adjusting for all variables included. This result could be partly attributable to the underestimation of any significant difference caused by grouping participants "at risk of malnutrition" and "malnutrition" as one variable, since those "at risk of malnutrition" could be differentiated to a lesser extent with the comparison group "well-nourished". Another explanation may be given by other variables not included in our analysis that have been proven to have a relation with malnutrition in dementia, such as nutrient intake, Apolipoprotein E status and inflammation $(49,50)$ or due to the sample size.

The frequency of multimorbidity, polymedication, and frailty in our sample was consistent with the prevalence of the same geriatric syndromes in older patients (51). An in-vitro study of our group in carriers of the same E280A genetic variant found that cholinergic neurons (differentiated from multipotent mesenchymal cells) display high levels of reactive oxygen species, 
loss of mitochondrial membrane potential and DNA fragmentation unlike other mesenchymal-derived cells (52). Therefore, to date, we cannot attribute the similarities between the geriatric syndromes in our middle-aged adults and older people only to the genetic variant. On the other hand, neuropathology that leads to cognitive impairment has been proven to directly affect indicators of frailty, which could be in our case, a possible explanation for our findings (53). Thus, the novelty of our study lies in the high frequency of geriatric syndromes, including undernutrition, in a group of patients with EO-ADAD, raising the importance of a complete clinical assessment with emphasis on nutrition of middle-aged adults with dementia.

\section{Strengths and limitations}

We analyzed a convenience sample $(\mathrm{N}=75)$ which causes a lack of adequate statistical power. The sampling methodology and cross-sectional design do not allow us to establish causality and therefore, results and conclusions should be read with precaution for other populations. Nevertheless, we acknowledge the value of our findings given the infrequent presentation of EO-ADAD. Healthy control groups should be desirable to contrast our hypothesis in further studies. Other forms of evaluation such as food-frequency and foodsecurity questionnaires and the measurement of plasma levels of nutrients should be applied in future research. Some limitations of the MNA in our context, are the questionable reliability and validity of responses from participants with dementia regarding self-perception, and the applicability of the thresholds of anthropometric variables validated in elderly populations but not in middle-aged adults. The MNA is a useful tool for grading nutritional status, but adaptations in anthropometric and self-graded parameters may be required for its use in EO-ADAD.

\section{Conclusion}

Undernourishment, determined by MNA score, is a frequent finding in patients with EO-ADAD, especially in those at later stages of the disease or those who are frail. However, BMI, brachial and calf circumferences as independent measures are not different between well and under-nourished groups. Polymedication and multimorbidity seem to have a direct relationship with an altered nutritional status. Likewise, frail patients with ADAD and those with severe dementia are more likely to be undernourished. Understanding the specific aspects of nutritional status that better describe this population may potentially improve diagnosis, treatment, and prognosis, slow cognitive decline, reduce comorbidity and impact quality of life and caregiver burden.

Author contributions: MGV was responsible for conducting the literature search, designing the research protocol, evaluating participants, interpreting results, writing the protocol and manuscript. EGC was responsible for designing the research protocol, evaluating participants, extracting and analyzing data, and interpreting results. DA was responsible for designing the protocol, evaluating participants, and interpreting results. CGH was responsible for conducting the literature search and writing the report. DV was responsible for extracting and analyzing data and creating the tables and figures. AJ contributed to the design of the research protocol, clinical evaluation of participants, and extraction of data. JEV contributed to the research protocol, evaluated participants, and extracted data. GDR was responsible for methodological review of the protocol, literature search, interpreting results and conclusions. CAT contributed to interpreting results and reviewing and editing the report. FL helped interpreting the results and provided feedback on the report.

Conflict of interest: Dr. Gomez Vega, Dr. Aguillon and Dr. Tobon report grants from Ministerio de Ciencia, Tecnología e Innovación-Minciencias, during the conduct of the study; Dr. Lopera reports grants from Minciencias, during the conduct of the study; grants from API COLOMBIA, outside the submitted work; Dr. Garcia-Cifuentes, Dr. Velez, Dr. Jaramillo-Jimenez, Dr. Vasquez, Dr. Gomez Henck, and Dr. Deossa Restrepo have nothing to disclose.

Ethical standards: Written informed consent was obtained from participants and their caregivers before study participation and publication. The study was approved by the ethics committee of the Institute of Medical Research - School of Medicine of the University of Antioquia act $005 / 2020$. All procedures followed were following the ethical standards of the Helsinki Declaration.

Acknowledgments: We thank the participants and family members enrolled in the longitudinal follow-up by the Group of Neurosciences of Antioquia for their kind contribution to science during the last 30 years. We also thank the Ministry of Sciences of Colombia and Colciencias for their support in providing research funding awarded to MGV in the Joven Investigador Profesional de Colciencias call (JIC-14-2019).

Funding sources: This research was supported by the Ministry of Sciences of Colombia and Colciencias, immersed in the project: "Identificación de biomarcadores preclínicos en enfermedad de Alzheimer a través de un seguimiento longitudinal de la actividad eléctrica cerebral en poblaciones con riesgo genético" executed by the Group of Neurosciences of Antioquia and Group Neuropsychology and Conduct (Project number: 111577757635). The sponsors had no role in the design and conduct of the study; in the collection, analysis, and interpretation of data; in the preparation of the manuscript; or the review or approval of the manuscript.

Availability of data and material: All authors have full access to the data.

\section{References}

1. Querfurth HW, Laferla FM. Alzheimer's Disease. N Engl J Med. 2010;362(4):329-44.

2. Acosta-Baena N, Sepulveda-Falla D, Lopera-Gómez CM, Jaramillo-Elorza MC, Moreno S, Aguirre-Acevedo DC, et al. Pre-dementia clinical stages in presenilin 1 E280A familial early-onset Alzheimer's disease: A retrospective cohort study. Lancet Neurol. 2011;10(3):213-20.

3. Lopera F, Ardilla A, Martínez A, Madrigal L, Arango-Viana JC, Lemere CA et al. Clinical features of early-onset Alzheimer disease in a large kindred with an E280A presenilin-1 mutation. J Am Med Assoc. 1997;277(10):793-9.

4. Ryman DC, Acosta-Baena N, Aisen PS, Bird T, Danek A, Fox NC, et al. Symptom onset in autosomal dominant Alzheimer disease. Neurology. 2014;83(3):253-60.

5. García-Ptacek S, Faxén-Irving G, Čermáková P, Eriksdotter M, Religa D. Body mass index in dementia. Eur J Clin Nutr. 2014;68(11):1204-9.

6. White H, Pieper C, Schmader K. The Association of Weight Change in Alzheimer's Disease with Severity of Disease and Mortality: A Longitudinal Analysis. J Am Geriatr Soc. 1998;46(10):1223-7.

7. Grundman M, Corey-Bloom J, Jernigan T, Archibald S, Thal LJ. Low body weight in Alzheimer's disease is associated with mesial temporal cortex atrophy. Neurology. 1996;46(6):1585-91.

8. Engelhart MJ, Geerlings MI, Meijer J, Kiliaan A, Ruitenberg A, Van Swieten JC, et al. Inflammatory Proteins in Plasma and the Risk of Dementia: The Rotterdam Study. Arch Neurol. 2004;61(5):668-72.

9. Stanciu I, Larsson M, Nordin S, Adolfsson R, Nilsson LG, Olofsson JK Olfactory Impairment and Subjective Olfactory Complaints Independently Predict Conversion to Dementia: A Longitudinal, Population-Based Study. J Int Neuropsychol Soc. 2014;20(2):209-17.

10. Kimura A, Sugimoto T, Kitamori K, Saji N, Niida S, Toba K, et al. Malnutrition is Associated with Behavioral and Psychiatric Symptoms of Dementia in Older Women with Mild Cognitive Impairment and Early-Stage. Nutrients. 2019;11(8):1-14.

11. Tamura B, Masaki K, Blanchette P. Weight Loss in Patients with Alzheimer's Disease. J Nutr Elder. 2008;26(3-4):21-38.

12. Little MO. Updates in nutrition and polypharmacy. Curr Opin Clin Nutr 
Metab Care. 2018;21(1):4-9.

13. Magierski R, Kłoszewska I, Sobow T. Evaluation of the influence of metabolic processes and body composition on cognitive functions: Nutrition and Dementia Project (NutrDem Project). Eur J Clin Nutr. 2014;68(11):1200-3.

14. Lefèvre-Arbogast S, Wagner M, Proust-Lima C, Samieri C. Nutrition and Metabolic Profiles in the Natural History of Dementia: Recent Insights from Systems Biology and Life Course Epidemiology. Curr Nutr Rep. 2019;8(3):256-69.

15. Nicolia V, Lucarelli M, Fuso A. Environment, epigenetics and neurodegeneration: Focus on nutrition in Alzheimer's disease. Exp Gerontol J. 2014;1-5.

16. Soto ME, Secher M, Gillette-Guyonnet S, Van Kan GA, Andrieu S, Nourhashemi F, et al. Weight Loss and Rapid Cognitive Decline in Community-Dwelling Patients with Alzheimer's Disease. J Alzheimer's Dis. 2012;28(3):647-54.

17. Vellas B, Lauque S, Gillette-Guyonnet S, Andrieu S, Cortes F, Nourhashemi F et al. Impact of nutritional status on the evolution of Alzheimer's disease and on response to acetylcholinesterase inhibitor treatment. J Nutr Heal Aging. 2005;9(2):75-80.

18. Chen Y, Sillaire AR, Dallongeville J, Skrobala E, Wallon D, Dubois B, et al Low Prevalence and Clinical Effect of Vascular Risk Factors in Early-Onset Alzheimer's Disease. J Alzheimer's Dis. 2017;60(3):1045-54.

19. Gu Y, Scarmeas N, Cosentino S, Brandt J, Albert M, Blacker D, et al. Change in Body Mass Index Before and After Alzheimer's Disease Onset. Curr Alzheimer Res. 2014;11(4):349-56.

20. Muñoz AM, Agudelo GM, Lopera FJ. Diagnóstico del estado nutricional de los pacientes con demencia tipo Alzheimer registrados en el Grupo de Neurociencias, Medellín, 2004. Biomédica. 2006;26(1):113-25.

21. Gerritsen AAJ, Bakker C, Verhey FRJ, de Vugt ME, Melis RJF, Koopmans RTCM, et al. Prevalence of Comorbidity in Patients With Young-Onset Alzheimer Disease Compared With Late-Onset: A Comparative Cohort Study. J Am Med Dir Assoc. 2016;17(4):318-23.

22. Panegyres PK, Chen HY. Differences between early and late onset Alzheimer's disease. Am J Neurodegener Dis. 2013;2(4):300-6.

23. Petersen RC, Doody R, Kurz A, Mohs RC, Morris JC, Rabins P V., et al. Current Concepts in Mild Cognitive Impairment. Arch Neurol. 2001;58(12):1985-92.

24. McKhann G, Knopman DS, Chertkow H, Hyman BT, Jack Jr CR, Kawas $\mathrm{CH}$, et al. The diagnosis of dementia due to Alzheimer's disease: Recommendations from the National Institute on Aging-Alzheimer's Association workgroups on diagnostic guidelines for Alzheimer's disease. Alzheimers Dement. 2012;7(3):263-9.

25. Reisberg B, Ferris S, De Leon M, Crook T. The Global Deterioration Scale for Assessment of Primary Degenerative Dementia. Am J Psychiatry. 1982;139(9):1136-9.

26. Clark RF, Hutton M, Fuldner M, Froelich S, Karran E, Talbot C et al. The structure of the presenilin 1 (S182) gene and identification of six novel mutations in early onset AD families. Nat Genet. 1995;11(2):219-22.

27. Barbe C, Jolly D, Morrone I, Wolak-Thierry A, Dramé M, Novella J-L, et al. Factors associated with quality of life in patients with Alzheimer's disease. BMC Geriatr. 2018 Jul;18(1):159.

28. Berndt S, Maier C, Schütz HW. Polymedication and medication compliance in patients with chronic non-malignant pain. Pain. 1993 Mar;52(3):331-9.

29. Navickas R, Petric V-K, Feigl AB, Seychell M. Multimorbidity: What Do We Know? What Should We Do? J Comorbidity. 2016;6(1):4-11.

30. da Câmara SMA, Alvarado BE, Guralnik JM, Guerra RO, Maciel ÁCC. Using the Short Physical Performance Battery to screen for frailty in youngold adults with distinct socioeconomic conditions. Geriatr Gerontol Int 2013;13(2):421-8.

31. Savva GM, Donoghue OA, Horgan F, O'Regan C, Cronin H, Kenny RA. Using Timed Up-and-Go to identify frail members of the older population. J Gerontol A Biol Sci Med Sci. 2013 Apr;68(4):441-6.

32. Alberti KGMM, Eckel RH, Grundy SM, Zimmet PZ, Cleeman JI, Donato KA, et al. Harmonizing the metabolic syndrome: A joint interim statement of the international diabetes federation task force on epidemiology and prevention; National heart, lung, and blood institute; American heart association; World heart federation; International . Circulation. 2009;120(16):1640-5.

33. World Health Organization. El estado físico: Uso e interpretación de la antropometría [Internet]. OMS, Serie de Informes Técnicos. 1993. Available from: http:/ / whqlibdoc.who.int/trs /WHO_TRS_854_spa.pdf?ua=1
34. Guerin $\mathrm{O}$, Soto ME, Brocker $\mathrm{P}$, Robert $\mathrm{PH}$, Benoit $\mathrm{M}$, Vellas B et al. Nutritional status assessment during Alzheimer's disease: results after one year (the REAL French Study Group). J Nutr Heal Aging. 2005;9(2):81-84.

35. Vellas B, Guigoz Y, Garry PJ, Nourhashemi F, Bennahum D, Lauque S, et al. The Mini Nutritional Assessment (MNA) and Its Use in Grading the Nutritional State of Elderly Patients. Nutrition. 1999;15(2):116-22.

36. Demirel B, Atasoy BM. Comparison of Three Nutritional Screening Tools to Predict Malnutrition Risk and Detect Distinctions Between Tools in Cancer Patients Receiving Radiochemotherapy. Nutr Cancer. 2018;70(6):867-73.

37. Nestle Nutrition Institute. Cribado Nutricional. Guía para rellenar el formulario Mini Nutricional Assessment [Internet]. Nestle Nutr Inst Workshop Ser. 2015. p. 20. Available from: http://www.mna-elderly.com/ forms/mna_guide_spanish.pdf

38. Torres VL, Vila-Castelar C, Bocanegra Y, Baena A, Guzmán-Vélez E, AguirreAcevedo DC, et al. Normative data stratified by age and education for a Spanish neuropsychological test battery: Results from the Colombian Alzheimer's prevention initiative registry. Appl Neuropsychol. 2019;0(0):115 .

39. Folstein MF, Folstein SE, McHugh PR. "Mini-Mental State" A practical method for grading the cognitive state of patients for the clinician. J psychiat Res. 1975;12:189-98.

40. Mahonei FI, Barthel DW. Functional Evaluation: The Barthel Index. Md State Med J. 1965;14:61-5.

41. Zou G. A Modified Poisson Regression Approach to Prospective Studies with Binary Data. Am J Epidemiol. 2004;159(7):702-6.

42. Barros AJD, Hirakata VN. Alternatives for logistic regression in crosssectional studies: An empirical comparison of models that directly estimate the prevalence ratio. BMC Med Res Methodol. 2003;3:1-13.

43. R Core Team. R: A language and environment for statistical computing. R Foundation for Statistical Computing [Internet]. Viena, Austria; 2019. Available from: https: / / www.r-project.org/.

44. Jang JW, Kim Y, Choi YH, Lee JM, Yoon B, Park KW, et al. Association of nutritional status with cognitive stage in the elderly Korean population: The Korean brain aging study for the early diagnosis and prediction of alzheimer's disease. J Clin Neurol. 2019;15(3):292-300.

45. Droogsma E, Van Asselt DZB, Scholzel-Dorenbos CJM, Van Steijn JHM, Van Walderveen PE, Van Der Hooft CS. Nutritional status of communitydwelling elderly with newly diagnosed Alzheimer's disease: Prevalence of malnutrition and the relation of various factors to nutritional status. J Nutr Heal Aging. 2013;17(7):606-10.

46. Tombini M, Sicari M, Pellegrino G, Ursini F, Insardá P, Di Lazzaro V. Nutritional Status of Patients with Alzheimer's Disease and Their Caregivers. J Alzheimer's Dis. 2016;54(4):1619-27.

47. Abellan Van Kan G, Vellas B. Is the mini nutritional assessment an appropriate tool to assess frailty in older adults? J Nutr Heal Aging. 2011;15(3):159-61.

48. Zadak Z, Hyspler R, Ticha A, Vlcek J. Polypharmacy and malnutrition. Curr Opin Clin Nutr Metab Care. 2013;16(1):50-5.

49. Olde Rikkert MGM, Verhey FR, Sijben JWC, Bouwman FH, Dautzenberg PLJ, Lansink $M$, et al. Differences in nutritional status between very mild Alzheimer's disease patients and healthy controls. J Alzheimer's Dis. 2014;41(1):261-71.

50. Volkert D, Chourdakis M, Faxen-Irving G, Frühwald T, Landi F, Suominen $\mathrm{MH}$, et al. ESPEN guidelines on nutrition in dementia. Clin Nutr. 2015;34(6):1052-73

51. Kane RL, Shamliyan T, Talley K, Pacala J. The association between geriatric syndromes and survival. J Am Geriatr Soc. 2012;60(5):896-904.

52. Soto-Mercado V, Mendivil-Perez M, Velez-Pardo C, Lopera F, JimenezDel-Rio M. Cholinergic-like neurons carrying PSEN1 E280A mutation from familial Alzheimer's disease reveal intraneuronal sAPP $\beta$ fragments accumulation, hyperphosphorylation of TAU, oxidative stress, apoptosis and $\mathrm{Ca} 2+$ dysregulation: Therapeutic implications. PLoS One [Internet] 2020;15(5):1-29. Available from: http://dx.doi.org/10.1371/journal. pone. 0221669

53. Robertson DA, Savva GM, Kenny RA. Frailty and cognitive impairment-A review of the evidence and causal mechanisms. Ageing Res Rev [Internet]. 2013;12(4):840-51. Available from: http://dx.doi.org/10.1016/j. arr.2013.06.004 